\title{
Sustainability, liveability and connectivity
}

\author{
Special Issue Editorial
}

By Magdalena Florek, Massimo Giovanardi

\begin{abstract}
Florek, M., \& Giovanardi, M. (2015). Sustainability, liveability and connectivity. Journal of Place Management and Development. Journal of Place Management and Development, Vol. 8 , No. 3 .
\end{abstract}

The previous Place Management Institute Conference, held in Manchester in 2013, delved into the different interpretations and applications of business principles to places. It helped to highlight the overlapping between different business perspectives, such as place management, place marketing and place branding. Once clarified, the boundaries between and among various business philosophies as applied to places, the time has come to better illuminate the context in which this phenomenon is happening; how is the "business of places" entangled with the global trends shaping the world today? What are its relationships with issues of sustainability, quality of life and the increasing global connectivity?

Such rationale underpinned the 3rd Place Management Institute Conference, which was hosted by Poznań University of Economics (Faculty of Management) on 6-8 May 2015, in partnership with Manchester Metropolitan and Stockholm Universities (Stockholm Programme of Place Branding). The conference was an occasion for scholars and practitioners to answer the questions that triggered the conference and to bring management and marketing of places even closer together. The selection of papers featured in this special issue illustrates the multifaceted debate generated across the three days of presentations. Contemporary society is often said to be increasingly projected towards models of sustainability and liveability. Accounts and evidence about the increasing degree of connectivity characterising the world both physically and virtually are usually emphasized and applauded, especially within business research. However, place management, marketing and branding are often implicated in unsustainable, unliveable and disconnected spaces. This special issue is an attempt to explore those "disconnections".

In the first paper, "Understanding Resident City Brand Disengagement", Menique Stuart and Andrea Insch try to engage with the main factors that may hinder the participation of citizens in the city brand process. Far from being a smooth and straightforward mechanism, the civic engagement in the creation and maintenance of a city brand might be difficult to achieve due to lack of brand awareness/knowledge, lack of brand identification, disapproval of local government actions and cynical attitudes towards involvement.

The utopian social cohesion challenged by the first paper is followed by Marta Herezniak and Justyna Anders-Morawska's study that lies at the borders of city marketing and public administration. The institutional context within which the city marketing and branding processes happen is not to be forgotten. The authors explore the efforts undertaken by the local government of the Polish city of Łódz to measure the effectiveness of its city brand strategy, by creating reliable and meaningful indicators. The issue of measurement represents one of the most needed aspects of this research area and is strictly connected to the problem of sustainability. Local managers would perhaps be more cautious in stressing the link between city marketing and sustainability if reliable measurement of place marketing campaign existed as a set of shared and established practices.

Both scholars and practitioners often adopt the concept of "place product" in a very straightforward way, regardless of its different nuanced components and the respective importance played in the life 
of citizens. The study of Kirill Rozhkov and Natalia Skriabina attempts to pave the way for a more rigorous and responsible approach to place product development by offering a analytical methodology that resonates with the organic models of Russian Formalism.

Food is an important component of place product and it is at the core of Tore Omholt's paper. In this fourth article, the author develops a theoretical framework to explain a culinary culture and place development. Food can be considered as a megatrend that brings together multiple aspects of a place and the author suggests that culinary activities have the potential to be an effective strategy for creating more liveable and connected territories.

Few studies can be found in the place branding literature about the adoption of branding principles in the context of Arabic countries, where political setting is significantly different from the case studies usually adopted by European and Northern-American scholars. The research note of Turki Shoaib and Ramin Keivani unravels the link between power and identity by highlighting the opportunities and pitfalls associated with place branding in the Middle East. This study also touches upon the challenge of making places liveable, as many cities in Middle East are designed from the scratch and they have to meet the needs of different stakeholders in their visions.

One of the most striking disconnections that place marketing and branding research have to deal with is the one between theory and practice. Mihalis Kavaratzis explores the widely acknowledged gap between place branding theory and practice in an attempt to address fundamental questions regarding the relationship between place branding scholars and practitioners. Can these two groups engage with each other's work and collaborate? The last paper is based on the closing discussion during the 3rd Place Management Institute Conference, where representatives of these two groups tried to identify not only the gaps, but foremost the solutions to better understand each other and as a result - to serve places better.

This special issue does not cover all challenges related to a place's sustainability, liveability and connectivity. We hope it is rather an impulse to talk further and more deeply about these issues, as they are going to be more and more relevant for place management and development in the future. In our future discussion, we have to change the perspective from short-term appealing solutions to long-term results that might happen and are often irreversible. We have to take a breath and to think again about the purpose of place management and development discipline which now should be future-oriented as never before.

Magdalena Florek

Department of Trade and Marketing, Poznan University of Economics, Poznan, Poland, and

Massimo Giovanardi

School of Management, University of Leicester, Leicester, UK 